\title{
Maternal obesity: a serious pediatric health crisis
}

\author{
Heidi M Harmon ${ }^{1}$ and Tamara S Hannon ${ }^{1}$
}

$\mathrm{n}$ this issue of Pediatric Research, Perrin et al. address maternal and child obesity in a study examining the markers of systemic inflammation and the subsequent development of obesity in premature infants (1). Undeniably, this study lends further support to what we know to be true, but are yet to effectively address-maternal obesity leads to poorer child health outcomes. Obesity in women of childbearing age is at an all-time high and is associated with multiple fetal complications, including preterm delivery (2). Preterm delivery, especially spontaneous delivery at $<28$ weeks and medically indicated delivery due to preeclampsia or diabetes is much more common in obese women $(2,3)$. Alarmingly, maternal pre-pregnancy obesity rates are at epidemic levels $(\sim 25 \%)$ within the United States, and obesity is increasing through much of the world $(4,5)$. Obesity complicates pregnancy by contributing to the development of pre-eclampsia, pregnancy-induced hypertension, gestational diabetes, thrombotic events, increased cesarean delivery, and through many of these conditions, contributes to the increasing maternal mortality rate in the United States (6). Maternal obesity is associated with an increased risk of miscarriage, fetal death, infant death, and major birth defects, including neural tube defects, cardiac, and orofacial abnormalities (7-9). Term infants born to mothers with obesity are more likely to experience perinatal asphyxia, meconium aspiration, neonatal seizures, or shoulder dystocia (10). Associations with subsequent neurodevelopmental disorders include increased risks of cerebral palsy, attention-deficit disorder, cognitive delay, and even autism (11-13). In addition to the direct health threats to children of obese mothers, these children are at much higher risk of becoming obese and developing cardiovascular morbidity or type 2 diabetes (14).

The biological roots of childhood obesity include not only the interplay of excess nutritional intake and decreased energy expenditure, but also the less understood elements of genetics, epigenetics, the in utero fetal environment. Factors implicated in the rapid increase of obesity globally include nutritional and environmental exposures that have the potential to increase systemic inflammation. Perrin et al. address the association between systemic inflammation in early infancy and the risk for developing very early childhood obesity (1). As part of the ELGAN (extremely low gestational age newborns, $<28$ weeks gestation) study, they present data on the association between early inflammation-related proteins in the blood of neonates and subsequent obesity at 2 years in a cohort of 882 ELGANs. Pregnancy complicated by obesity is known to be associated with increased maternal systemic and placental inflammatory responses (15-17). However, cord blood collected from the term infants of obese mothers has not been shown to have a parallel increase in inflammatory markers $(15,17)$. In the current study, infants with spontaneous indications for delivery were more likely to have markers of systemic inflammation on the first postnatal day compared to children delivered due to maternal cause. In multivariable models, only elevated IL-6 on day 1 was associated with the development of obesity (odds ratio: 2.9; $95 \%$ confidence limits: $1.2,6.8$ ). These results parallel the data previously published, showing only small differences in the inflammatory patterns in infants born to mothers with obesity, as compared with mothers without obesity (18). At this time, evidence does not support the conclusion that the transference of inflammatory maternal proteins to the fetus plays a significant role in the development of childhood obesity in preterm infants, and further research is needed to understand the role of chronic inflammation and the development of increased adiposity in infants.

Perrin et al. also provide more data on the evolving pattern of obesity in the ELGAN population. While $20 \%$ of their mothers were obese, an alarming $14 \%$ of ELGANs in their cohort were already obese or overweight by 2 years of age. The longitudinal data in other ELGAN cohorts suggest that the typical pattern of growth in extreme preterm infants is that of growth failure during infancy followed by an accelerated catch-up during childhood through adolescence, which often crosses the growth and the BMI percentiles (19-21). Experience and previous research support the premise that the children in this ELGAN cohort will likely experience additional excessive weight gain in later childhood, which will result in an even higher rate of obesity in adolescence. The risk posed by the expanding obesity rate among ELGAN children is especially concerning due to the high baseline

${ }^{1}$ Divisions of Neonatology (HH) and Pediatric Endocrinology and Diabetology (TH), Department of Pediatrics, Indiana University School of Medicine, Indianapolis, Indiana. Correspondence: Tamara S. Hannon (tshannon@iu.edu)

Received 17 February 2018; accepted 4 March 2018; advance online publication 2 May 2018. doi:10.1038/pr.2018.50 


\section{Comment $\mid$ Harmon and Hannon}

burden of chronic health issues these children face. ELGAN populations have higher cardiovascular disease risk, including higher LDL cholesterol, systolic blood pressure, resting heart rate, and pulse pressures (22-24). Combining obesity and the subsequent risk of diabetes with the baseline risk of cardiovascular disease likely creates a substantial risk of accelerated atherosclerosis and early cardiovascular disease in this population.

Previous and current research on the familial cycle of obesity and increased related chronic health problems in youth have public health policy implications. Perrin et al. found that ELGANs who developed obesity by the age 2 years were significantly more likely, than healthy weight children, to have a mother who was obese before her pregnancy. Although maternal pre-pregnancy obesity is one of the strongest predictors of childhood obesity, it remains unclear how much of this association is related to genetic predisposition, intrauterine environmental influences, or exposure to a similar environment that fosters obesity in the mother. It is clear that societal influences that increase the consumption of calories and decrease opportunities for physical activity are the key contributing factors to childhood obesity, and that public health policies will be needed to make the necessary changes to impact the problem.

Working at the local level, programs supported by the Robert Wood Johnson Foundation (RWJF) have made contributions to advocacy to reduce childhood obesity. Voices for Health Kids was established in 2012 by the American Heart Association and the RWJF to build and support an infrastructure that will advance policies to address childhood obesity. This includes providing grants to organizations already involved in childhood obesity and equipping the advocates with knowledge, skills, and research to help them develop and execute effective messages to help increase the likelihood of successful policy initiatives. Recent research found that states with active Voices for Healthy Kids campaigns enacted $50 \%$ more policies to reduce childhood obesity and improve community health than they did before the campaign was implemented in $2013(25,26)$. School-based interventions that combined diet and physical activity components may also hold the promise for childhood obesity prevention worldwide (27).

There are scientifically validated programs for reducing obesity in women, including programs based on the effective National Diabetes Prevention Program (28-30), hospitalbased programs (31), behavioral interventions and health coaching $(32,33)$, and medically approved commercial weight loss programs $(30,34,35)$. Programs such as these are effective, yet are scarcely utilized due to the lack of funding and insufficient health care coverage for preventive services covering weight management (36-38). Further research in a variety of disciplines (biological, social, and health policy) is needed to better understand how to implement the policies that allow wider participation in such programs and encourage behaviors that promote healthier weights. Policies to reduce obesity should not only apply to youth, or to women of child-bearing age, or to adults with prediabetes, or those who recently had a heart attack. Efforts to reduce obesity should be broad and inclusive. Tobacco control is one example of governmental policy that has resulted in improved health of the entire population. It is yet to be seen whether similar regulations to introduce a soda tax or eliminate advertising of high-sugar food and drinks could reduce obesity, but there are signs that these efforts could benefit population health $(39,40)$.

In conclusion, obesity in women of child-bearing age is a true public health crisis, leading to increased morbidity and mortality in women and children. We propose that research, innovative strategies, and public health policy initiatives focusing on reducing the rates of obesity in women of childbearing age are desperately needed. Reductions in maternal obesity would improve not only the maternal health but would have countless benefits, including reducing infant mortality, premature birth, rates of neurodevelopmental impairment and disorders, childhood obesity, cardiovascular disease, and type 2 diabetes.

Disclosure: The authors declare no conflict of interest.

\section{REFERENCES}

1. Perrin EM, O'Shea TM, Skinner AC, et al. Elevations of inflammatory proteins in neonatal blood are associated with obesity and overweight among 2-year-old children born extremely premature. Pediatr Res 2018doi:10.1038/pr.2017.313.

2. Cnattingius S, Villamor E, Johansson S, et al. Maternal obesity and risk of preterm delivery. JAMA 2013;309:2362-70.

3. Kim SS, Mendola P, Zhu Y, Hwang BS, Grantz KL. Spontaneous and indicated preterm delivery risk is increased among overweight and obese women without prepregnancy chronic disease. BJOG 2017;124:1708-16.

4. Poston L, Caleyachetty R, Cnattingius S, et al. Preconceptional and maternal obesity: epidemiology and health consequences. Lancet Diabetes Endocrinol 2016;4:1025-36.

5. Deputy NP, Dub B, Sharma AJ. Prevalence and trends in prepregnancy normal weight - 48 States, New York City, and District of Columbia, 2011-2015. MMWR Morb Mortal Wkly Rep 2018;66:1402-7.

6. Athukorala C, Rumbold AR, Willson KJ, Crowther CA. The risk of adverse pregnancy outcomes in women who are overweight or obese. BMC Pregnancy Childbirth 2010;10:56.

7. Stothard KJ, Tennant PW, Bell R, Rankin J. Maternal overweight and obesity and the risk of congenital anomalies: a systematic review and meta-analysis. JAMA 2009;301:636-50.

8. Johansson S, Villamor E, Altman M, Bonamy AK, Granath F, Cnattingius S. Maternal overweight and obesity in early pregnancy and risk of infant mortality: a population based cohort study in Sweden. BMJ 2014;349: g6572.

9. Aune D, Saugstad OD, Henriksen T, Tonstad S. Maternal body mass index and the risk of fetal death, stillbirth, and infant death: a systematic review and meta-analysis. JAMA 2014;311:1536-46.

10. Persson M, Johansson S, Villamor E, Cnattingius S. Maternal overweight and obesity and risks of severe birth-asphyxia-related complications in term infants: a population-based cohort study in Sweden. PLoS Med 2014;11:e1001648.

11. Sanchez CE, Barry C, Sabhlok A, et al. Maternal pre-pregnancy obesity and child neurodevelopmental outcomes: a meta-analysis. Obes Rev 2017;19:464-84.

12. Forthun I, Wilcox AJ, Strandberg-Larsen K, et al. Maternal prepregnancy BMI and risk of cerebral palsy in offspring. Pediatrics 2016;138: e20160874. 


\section{Maternal obesity: a health crisis $\mid$ Comment}

13. Wang Y, Tang S, Xu S, Weng S, Liu Z. Maternal body mass index and risk of autism spectrum disorders in offspring: a meta-analysis. Sci Rep 2016;6:34248.

14. Godfrey KM, Reynolds RM, Prescott SL, et al. Influence of maternal obesity on the long-term health of offspring. Lancet Diabetes Endocrinol 2017;5:53-64.

15. Aye IL, Lager S, Ramirez VI, et al. Increasing maternal body mass index is associated with systemic inflammation in the mother and the activation of distinct placental inflammatory pathways. Biol Reprod 2014;90:129.

16. Abbassi-Ghanavati M, Alexander JM, McIntire DD, Savani RC, Leveno KJ. Neonatal effects of magnesium sulfate given to the mother. Am J Perinatol 2012;29:795-9.

17. Basu S, Haghiac M, Surace P, et al. Pregravid obesity associates with increased maternal endotoxemia and metabolic inflammation. Obesity 2011;19:476-82.

18. van der Burg JW, Allred EN, McElrath TF, et al. Is maternal obesity associated with sustained inflammation in extremely low gestational age newborns? Early Hum Dev 2013;89:949-55.

19. Hack M, Schluchter M, Margevicius S, Andreias L, Taylor HG, Cuttler L. Trajectory and correlates of growth of extremely-low-birth-weight adolescents. Pediatr Res 2014;75:358-66.

20. Roberts G, Cheong J, Opie G, et al. Growth of extremely preterm survivors from birth to 18 years of age compared with term controls. Pediatrics 2013;131:e439-45.

21. Saigal S, Stoskopf B, Streiner D, Paneth N, Pinelli J, Boyle M. Growth trajectories of extremely low birth weight infants from birth to young adulthood: a longitudinal, population-based study. Pediatr Res 2006;60: 751-8.

22. Parkinson JR, Hyde MJ, Gale C, Santhakumaran S, Modi N. Preterm birth and the metabolic syndrome in adult life: a systematic review and metaanalysis. Pediatrics 2013: 131.

23. Hovi P, Vohr B, Ment LR, et al. Blood pressure in young adults born at very low birth weight: adults born preterm international collaboration. Hypertension 2016;68:880-7.

24. Kerkhof GF, Breukhoven PE, Leunissen RW, Willemsen RH, HokkenKoelega AC. Does preterm birth influence cardiovascular risk in early adulthood? J Pediatr 2012;161:390-6 e1.

25. Bleich SN, Jones-Smith J, Jones H, O'Hara M, Rutkow L. The voices for healthy kids campaign and US State Legislation to prevent childhood obesity. Am J Public Health 2016;106:436-9.

26. Rutkow L, Jones-Smith J, Walters HJ, O'Hara M, Bleich SN. Factors that encourage and discourage policy-making to prevent childhood obesity: experience in the United States. J Public Health Policy 2016;37:514-27.

27. Bleich SN, Vercammen KA, Zatz LY, Frelier JM, Ebbeling CB, Peeters A. Interventions to prevent global childhood overweight and obesity: a systematic review. Lancet Diabetes Endocrinology 2017;6:332-46.
28. Brunisholz KD, Joy EA, Hashibe M, et al. Stepping back to move forward: evaluating the effectiveness of a diabetes prevention program within a large integrated healthcare delivery system. J Healthc Qual 2017;39: 278-93.

29. Ritchie ND, Sauder KA, Fabbri S. Reach and effectiveness of the national diabetes prevention program for young women. Am J Prev Med 2017;53: $714-8$.

30. Marrero DG, Palmer KN, Phillips EO, Miller-Kovach K, Foster GD, Saha CK. Comparison of commercial and self-initiated weight loss programs in people with prediabetes: a randomized control trial. Am J Public Health 2016;106:949-56.

31. McGiveron A, Foster S, Pearce J, Taylor MA, McMullen S, Langley-Evans SC. Limiting antenatal weight gain improves maternal health outcomes in severely obese pregnant women: findings of a pragmatic evaluation of a midwife-led intervention. J Hum Nutr Diet 2015;28 (Suppl 1): 29-37.

32. Herring SJ, Cruice JF, Bennett GG, et al. Intervening during and after pregnancy to prevent weight retention among African American women. Prev Med Rep 2017;7:119-23.

33. Herring SJ, Cruice JF, Bennett GG, Rose MZ, Davey A, Foster GD. Preventing excessive gestational weight gain among African American women: a randomized clinical trial. Obesity 2016;24:30-6.

34. Baetge C, Earnest CP, Lockard B, et al. Efficacy of a randomized trial examining commercial weight loss programs and exercise on metabolic syndrome in overweight and obese women. Appl Physiol Nutr Metab 2017;42:216-27.

35. Foster GD, Wadden TA, Lagrotte CA, et al. A randomized comparison of a commercially available portion-controlled weight-loss intervention with a diabetes self-management education program. Nutr Diabetes 2013; 3:e63.

36. Robertson R, Squires D, Garber T, Collins SR, Doty MM. Oceans apart: the higher health costs of women in the U.S. compared to other nations, and how reform is helping. Issue Brief (Commonw Fund) 2012;19:1-20.

37. Collins SR, Robertson R, Garber T, Doty MM. Young uninsured, and in debt: why young adults lack health insurance and how the Affordable Care Act is helping: findings from the Commonwealth Fund Health Insurance Tracking Survey of Young Adults, 2011. Issue Brief (Commonw Fund) 2012;14:1-24.

38. Doshi RS, Bleich SN, Gudzune KA. Health professionals' perceptions of insurance coverage for weight loss services. Obes Sci Pract 2017;3:384-9.

39. Nakhimovsky SS, Feigl AB, Avila C, O'Sullivan G, Macgregor-Skinner E, Spranca M. Taxes on sugar-sweetened beverages to reduce overweight and obesity in middle-income countries: a systematic review. PLoS ONE 2016;11:e0163358.

40. Sturm R, Powell LM, Chriqui JF, Chaloupka FJ. Soda taxes, soft drink consumption, and children's body mass index. Health Aff 2010;29: $1052-8$. 